\title{
NOTA INTRODUTÓRIA SOBRE AS METODOLOGIAS UTILIZADAS NA EDUCAÇÃO ESPECIAL PARA O ENSINO FUNDAMENTAL NAS ESCOLAS NO ORBES PÚBLICO E PRIVADO BRASILEIRO
}

\author{
Erotildes Emmanuelly Ferreira Belarmino ${ }^{1}$ \\ Diógenes José Gusmão Coutinho²
}

\begin{abstract}
Resumo: A educação inclusiva como um dos eixos da educação especial, oferece uma gama de informações muito importante para professores titulares, professores de apoio, pais e equipe gestora, abarcando uma densa bagagem para se obter uma educação de qualidade, abordando a deficiência física, transtornos globais do desenvolvimento, autismo e deficiência intelectual neste trabalho, com o intuito de mostrar diferentes estratégias de ensino para os estudantes com deficiência. Diante do exposto, o presente trabalho tem como objetivo discutir a inclusão escolar com a perspectiva da educação especial voltada para as deficiências intelectuais, física e os transtornos globais do desenvolvimento e autismo, visando tratar sobre o uso de metodologias e experiências para a diversidade das práticas pedagógicas onde visam promover procedimentos e estratégias de ensino para que estudantes com necessidades especiais tenha acesso à inclusão.
\end{abstract}

Palavras-chave: Educação especial. Educação inclusiva. Metodologia.

\section{INTRODUCTORY NOTE ON THE METHODOLOGIES USED IN SPECIAL EDUCATION FOR TEACHING IN FUNDAMENTAL SCHOOLS IN BRAZILIAN PUBLIC AND PRIVATE SPACES}

\begin{abstract}
An inclusive education as one of the axes of special education, offers a series of very important information for teachers, support teachers, parents and a team of managers, who include a density bag to obtain a quality education, addressing physical

\footnotetext{
${ }^{1}$ Graduanda em Pedagogia pela FAJOLCA. Pós-graduação Lato Sensu em Docência no ensino superior pela Faculdade dos Guararapes, Pós-graduação em Educação Especial e Inclusiva pela Faculdade Alpha, Pós-graduação em Pesquisa Avançada pela Faculdade Alpha e Mestranda pela Atenas College University. E-mail: polkuoi@gmail.com.

${ }^{2}$ Graduado em Biologia Pela Universidade Federal Rural de Pernambuco (UFRPE), Doutor em Biologia pela Universidade Federal de Pernambuco, Professor e Coordenador do Curso de Mestrado em Direito Pela Faculdade ALPHA - Atenas College University - Estados Unidos. Email.: alphadiogenes@gmail.com.
} 


\section{Revista Ibero-Americana de Humanidades, Ciências e \\ Educação \\ Produção e democratização do conhecimento na Ibero-América}

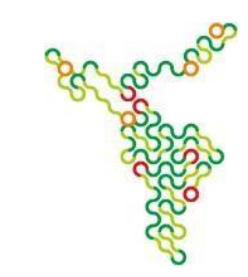

activity, disorders development costs and autism and intellectual disabilities in this work, in order to show different teaching strategies for students with disabilities. Given the above, this paper aims to discuss school inclusion with a special education perspective focused on intellectual, physical disabilities and global developmental and autism disorders, treatment on the use of methods and studies for a variety of pedagogical practices where o aim to promote procedures and teaching strategies for students with special needs to have access to inclusion.

Keywords: Special education. Inclusive education. Methodology.

\section{INTRODUÇÃO}

Utilizando eixos a educação inclusiva (PEREIRA, 2017) com a intenção de pontuar as necessidades educativas de cada aluno, um desses eixos é a educação especial, que segundo (SMITH, 2009) deve conter uma gama de informações muito importante para professores titulares, professores de apoio, pais e equipe gestora, abarcando uma densa bagagem para se obter uma educação de qualidade, abordando a deficiência física, transtornos globais do desenvolvimento, autismo e deficiência intelectual neste trabalho, com o intuito de mostrar diferentes estratégias de ensino para os estudantes com deficiência, sabe-se, ainda, que a escola deve representar ousadia e precisa romper barreiras, revendo suas atitudes, concepções e paradigmas, desenvolvendo o potencial dessas pessoas, definindo, portanto, sua responsabilidade sobre o respeito e a valorização da diversidade.

A escola é um dos suportes que a sociedade tem, para introduzir assuntos de quebra preconceitos, desta forma, as pessoas que tinham deficiências no passado e que eram excluídas da sociedade, passam a ter voz e expressão no convívio com os demais.

Sabendo que já existem leis (DUTRA, 2007), que amparam as pessoas que têm limitações, sendo a educação um direito de todos um verdadeiro exercício da cidadania, mostrando que a escola é um ambiente de igualdade e qualificação pessoal e profissional, e considerando ainda, que existe ainda muito para se fazer, como, por exemplo, as leis, que mesmo sendo decretadas são implantadas de modo lento e parcial, muitas vezes sendo ignoradas pela sociedade e pelos órgãos públicos, se faz necessário que o professor observe o aluno mesmo diante das adversidades encontradas com os seus diferentes contextos, a inclusão das pessoas com deficiência é um fato que também deve ser efetivado em sala de aula, não apenas ingressá-los no ensino regular, mas prepará-los para 


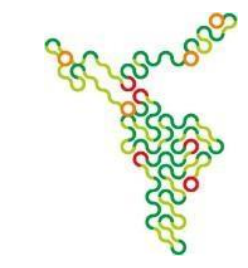

produzir e viver na sociedade. (BRASIL, 2002).

Os profissionais da educação deverão estar ciente do compromisso do seu trabalho, visando promover a inclusão e um apoio para os mesmos, o presente trabalho tem como objetivo discutir a inclusão escolar com a perspectiva da educação especial voltada para as deficiências intelectuais, física e os transtornos globais do desenvolvimento e autismo, visando tratar sobre o uso de metodologias e experiências para a diversidade das práticas pedagógicas onde visam promover procedimentos e estratégias de ensino para que estudantes com necessidades especiais tenha acesso à inclusão.

Observa-se que para à aprendizagem é fundamental um esforço que acontece por meio das interações sociais, a mediação do professor traz um desafio importante para a estimulação visando uma maneira atrativa para que o aluno adquira o conhecimento, o professor possibilita um desafio no seu trabalho, para transformar sua metodologia de ensino, assim sendo, criasse uma oportunidade para as regras de convivência é o princípio da formação da identidade, e para o professor, abre-se uma porta de conhecimento e de autovalorização pessoal. (CARVALHO, 2016)

sabendo disto segue algumas dicas para a inclusão do aluno com deficiência intelectual. (BRASIL, 1999)

Nos casos da idade cronológica apresentar alterações, deve-se promover a interação social de alunos com a mesma idade, assim, participaram das mesmas atividades e aprenderam valores, comportamentos e atitudes com crianças que tenham a mesma faixa etária. Muitas escolas pelo fato do aluno apresentar estas alterações, tende a regredir o aluno para salas que tenham "a mesma idade mental da criança" ocorrendo assim, uma infantilização, onde não contribui para seu desenvolvimento e retarda ainda mais o processo de desenvolvimento psicossocial.

Ter ciência que é preciso redobrar a atenção, sabendo que o ritmo é bem mais lento de aprendizado, o professor deve utilizar maneiras curtas e objetivas, a partir de contextos reais, dividindo as tarefas em partes se acaso o nível de dificuldade for elevado, fazer adaptações de conteúdos sempre que necessário.

O profissional da educação inclusiva deve elevar a autoestima do aluno, não enfatizando as dificuldades e os erros, mas sim valorizando os acertos ou tentativas. 


\section{Revista Ibero-Americana de Humanidades, Ciências e \\ Educação \\ Produção e democratização do conhecimento na Ibero-América}

Elaborar um quadro com a sequência de atividades que realizarão ao longo do dia é muito importante, pois, compreenderão as instruções que serão vivenciadas. O professor com este quadro também estimula o pensamento, quando alguma atividade terminar, fará uma simples pergunta como: "O que vêm agora, crianças?"

No final da aula, convém uma revisão, para fixar na memória, sanar possíveis dúvidas e observar o aprendizado da turma.

Ter cuidado com o planejamento das aulas, pois, alguns alunos com deficiência intelectual também apresentam limitações motoras, por isto elaborar estratégias que não prejudiquem o aprendizado é muito importante.

Elaborar uma aula dinâmica para trabalhar a linguagem é também trazer diferentes elementos como, música, artes, expressões corporais, entre outras.

Utilizar diversos trabalhos em grupos ou em duplas para que com o aprendizado cooperativo a criança melhore não só a adaptação, mas sim, a linguagem, a absorção de conteúdo.

Ao avaliar o aluno o professor deverá observar seu progresso individual e suas habilidades naturais, é não compará-lo com o restante da turma. Reprovar o aluno ao fim do ano também prejudica sua autoestima, ao observar a evolução da sua turma e ele continuar estagnado na mesma sala.

Ensiná-lo a pedir ajuda caso precise, como também posicionar o aluno próximo ao professor, nas primeiras carteiras, para que o professor possa ficar sempre atento ao aluno.

Muitos alunos fazem tratamentos psicológicos ou clínicos, é importante uma parceria entre a escola e as instituições que fazem o acompanhamento em cito o para abordar questões referentes, ao desenvolvimento integral deste aluno em sala. Essa parceria tem bons resultados, com trocas valiosas de informações, o professor deve checar com os pais, fazendo o levantamento necessário para que aconteça a parceria.

O professor com o resultado do teste de inteligência em mãos, poderá ter bons resultados educacionais, ajudando o seu planejamento, e não é só isso, fará acontecer a observação em diferentes ambientes, como a interação social, com as atividades propostas, moldando as aulas aos interesses particulares do aluno, observando suas potencialidades, para facilitar o seu aprendizado. O teste não será fixado como medida, 


\section{Revista Ibero-Americana de Humanidades, Ciências e \\ Educação \\ Produção e democratização do conhecimento na Ibero-América}

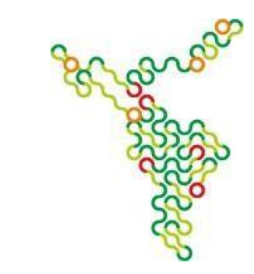

pois o profissional da educação, precisa reforçar a limitação para se obter o aprendizado. O professor, neste caso, precisa desenvolver a criatividade, a capacidade de conhecer o mundo e a si mesmo, entre outros. (DUTRA, 2007)

A deficiência intelectual pode ser caracterizada de causas estruturais, como também, pode ser construída, pela falta de estimulação, de convívio social e interações. O termo, síndrome, é utilizado para um conjunto de características, estas síndromes são mais comuns em alunos que apresentam a deficiência intelectual, abordaremos agora as mais comuns:

\subsubsection{Síndrome de Down}

Esta síndrome ocorre devido a um acidente genético, onde é causada pela presença de três cromossomos 21 em todas ou na maior parte das células de um indivíduo.

Diante deste quadro, muitos educadores têm dificuldades de alfabetizar os alunos, é importante esclarecer possíveis dúvidas como as características físicas principais nas crianças com Síndrome de Down, hipotonia: flacidez muscular e diminuição na força; deficiência intelectual: limitações no intelecto dificultando a aprendizagem; aparência física: olhos, fissura na pálpebra, dedos curtos, mãos-largas, prega palmar única, ponte nasal achatada, pescoço curto, articulação flexível, língua protusa, entre outros; condições fisiológicas e intercorrências orgânicas: deficiência motora, problemas cardíacos, problemas na visão e audição, disfunção na tireoide, deficiência imunológica. Seu grau pode variar de leve a grave.

O professor deve trabalhar em sala, conteúdos adaptados abordando a estimulação do desenvolvimento motor, cognitivo e intelectual do aluno. Apesar do comprometimento Intelectual, muitas crianças conseguem se alfabetizar. (JOIA, 2018)

\subsubsection{Síndrome de Rett}

Ao contrário da Síndrome de Down que é comum no Brasil, a Síndrome de Rett é extremamente rara, é genético e ocorre com mais frequência em meninas onde se desenvolve normalmente até o primeiro ano de vida, mas começam a estagnar o seu desenvolvimento, apresentando desaceleração do crescimento da calota craniana, problemas na coordenação, movimentos e comunicação, isolamento. No princípio foi erroneamente diagnosticada como autismo. Esta síndrome também pode ser encontrada em alunos com deficiência múltipla. 
O professor em sala de aula deve promover a estimulação sensorial para também aprimorar funções intelectuais ligadas a percepção, memória, linguagem e aprendizagem, estimular os sentidos: audição, visão, olfato e paladar, aprimorar as habilidades psicomotoras e proprioceptivas. (CARNEIRO, 2007).

\subsection{Transtornos Mentais- Transtornos globais do desenvolvimento e Autismo}

Também conhecido como TGD, englobam diferentes transtornos os principais são o Autismo, a Psicose, a Síndrome de Asperger, a Síndrome de Rett e a Esquizofrenia. Estes são distúrbios nas interações sociais e costumam a se manifestar nos primeiros cinco anos de vida. Vamos observar seus diferentes transtornos dando maior ênfase ao autismo. (HONORA; FRIZANCO, 2009).

\subsubsection{Psicose}

É uma desorganização da personalidade podendo fazer perder o sentido do real e imaginário, as características das crianças que tem o perfil psicótico são: dificuldade de se afastar da mãe; deficiência do desenvolvimento da fala; problemas na compreensão do que vê; falta da identidade pessoal; resistência a mudança de rotina ou ambientes.

\subsubsection{Esquizofrenia}

A desorganização da personalidade se dá por um severo transtorno do funcionamento do cérebro, as crianças no início da esquizofrenia têm características como o isolamento social, distúrbio de pensamento, rompe relacionamentos, recusa alimentar, distância da realidade, ansiedade, transtorno bipolar, delírios, depressão.

\subsubsection{Transtorno de Asperger}

Apresentam limitação na interação social, porém não sofrem com comprometimento cognitivo grave nem com o desenvolvimento da fala, na infância apresentam dificuldades no desenvolvimento motor, também tem como características, insistência com partes dos objetos e costuma ocorrer mais em meninos.

\subsubsection{Autismo}

O autismo é um transtorno invasivo do desenvolvimento, que aparece nos três primeiros anos de vida, onde compromete o indivíduo a conviver socialmente na comunidade, interferindo na sua comunicação e interação social.

É um tema atual no Brasil, há um pouco mais de dez anos que se vem falando 


\section{Revista Ibero-Americana de Humanidades, Ciências e \\ Educação \\ Produção e democratização do conhecimento na Ibero-América}

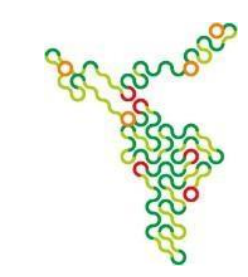

sobre a implementação de práticas inclusivas, como a Coordenadoria Nacional para Integração da pessoa Portadora de Deficiência (CORDE), eles fizeram o "I Congresso Nacional de Autismo" conscientizando as áreas políticas, educacionais, médicas, como também mostrando que o tema faz superar as desigualdades. E em maior de 2013, o Manual Diagnóstico e Estatístico de Transtorno Mentais (DSM-V) mostrou novos diagnósticos e alterações para nomes de doenças dentre esses acréscimos, o autismo, foi incorporado.

Sobre o "espectro autista", é importante conhecer os diferentes graus, pois, na sua constatação se modifica estratégias básicas do ensino, onde o grau vai do leve até o severo. Algumas características das crianças com autismo é: abanar as mãos, pula constantemente no mesmo lugar, balança-se incessantemente, comportamentos repetitivos, não faz contato visual, obsessão por certo objetos, para pedir algo acompanha a pessoa até o lugar onde está o que quer, não reage a certos sons, não gosta que toquem, não responde quando chamado, não gostam de mudar a rotina, sente raiva ou ri sem nenhuma razão, não reconhece sua presença ao chegar a um ambiente, tem interesses restritos.

Como no autismo, existem diferentes graus, que podem variar de leve à grave, diferenciando a intervenção pedagógica, como também seus materiais adaptativos, por isso é interessante conhecer todos os níveis.

O professor para intervir em sala neste caso, utiliza linguagem objetiva, abordagens sensoriais, adapta o currículo, provas e avaliações, utiliza jogos, evita atividades longas, elabora trabalhos em grupos ou em duplas para que haja a interação, observa o interesse do aluno assim elaborando aulas atrativas para ele, apresenta quadro de rotina nas aulas, solicitando para que faça a frequência do quadro ou questionando a ordem, estimular o pensamento lógico com atividades, incentivá-lo usando o vínculo afetivo. (ZAPPAROLI, 2014)

É muito importante frisar que o Transtorno do Espectro Autista não está relacionado, à deficiência intelectual, uma criança autista pode também apresentar deficiência intelectual, mas também pode apresentar condições singulares, sendo assim, pode apresentar o autismo, surdez, e outras condições.

Crianças autistas podem apresentar deficiência em um ou mais sentidos, porém 
possui inteligência, há crianças com altas habilidades que tem autismo, por isso o autismo não é considerado uma deficiência intelectual, assim ficando neste trabalho com um tópico à parte.

\subsection{DA DEFICIÊNCIA FÍSICA}

A deficiência física e descrita na lei $n^{\circ}$ 5296/04 como, alteração completa ou parcial de um, ou mais segmentos do corpo humano, acarretando o comprometimento da função física, apresentando-se sob a forma de paraplegia, paraparesia, monoplegia, monoparesia, tetraplegia, tetraparesia, triplegia, triparesia, hemiplegia, hemiparesia, ostomia, amputação ou ausência de membro, paralisia cerebral, nanismo, membros com deformidade congênita ou adquirida, exceto as deformidades estéticas e as que não produzem dificuldades para o desempenho de funções;

A disfunção do movimento de um ou mais membros sendo eles superiores, inferiores ou em ambas as partes, ocorrendo conforme o grau de comprometimento se tem pelo nome de paralisia ou paresia. (ROPOLI, MANTOAN \& SANTOS, 2010)

A paralisia é a perda da contração muscular voluntária, fazendo o movimento fica impossível, essa perda pode ir do córtex cerebral até o próprio músculo; já o termo paresia é utilizado quando o movimento é apenas limitado, como uma "semi paralisia", está mobilidade está abaixo do normal, fazendo assim, um comprometimento parcial da força muscular, precisão e amplitude do movimento e resistência muscular.

Existe uma classificação dos quadros da paralisia cerebral, ela foi sugerida por WYLLIE, e mostra a relação e os diferentes tipos de acometimentos como:

- Quanto ao tônus muscular:

Hipertônico: Termo utilizado quando o indivíduo apresenta dificuldades de desenvolver movimentos quando o tônus é elevado.

Flutuante: divide-se em duas partes sendo elas: atetóide- tônus muscular instável e flutuante e; atáxica- hipotônica.

Hipotônico: quadro isolado e raro na paralisia cerebral.

Misto: Termo utilizado quando o indivíduo apresenta diferentes associações das formas citadas acima.

- Distribuição corporal: 


\section{Revista Ibero-Americana de Humanidades, Ciências e \\ Educação \\ Produção e democratização do conhecimento na Ibero-América}

Tetraplegia: Termo utilizado quando o comprometimento atinge todos os quatro membros.

Paraplegia: Termo utilizado quando o comprometimento e apenas nos membros inferiores.

Hemiplegia: Termo utilizado quando o comprometimento é total ou parcial da metade lateral do corpo.

Diplegia: Termo utilizado quando o comprometimento acomete as mesmas partes de ambos os lados do corpo, assim formando a paralisia bilateral.

Monoplegia: Termo utilizado quando o comprometimento acomete um só membro ou grupo muscular.

As causas da deficiência física podem ser de origem congênitas ou podem ser adquiridas ao longo da vida, essas causas são de formas variadas desde:

- Paralisia Cerebral: por prematuridade, anoxia perimental, rubéola, trauma de parto, subnutrição e outras.

- Hemiplegias: acidente vascular cerebral, aneurisma cerebral, tumor cerebral, diabéticos e outras.

- Lesão Medular: ferimento por arma de fogo ou arma branca, mergulho em águas rasas, quedas, degenerativos, acidentes de trânsito, traumatismo direto, quedas e outras

- Amputações: causas vasculares, traumas, malformações congênitas, causas metabólicas e outras.

A escola também deve investir em recursos para que melhor atenda o aluno, assim garante o acesso físico ao aluno e até mesmo o material específico para ele, como, por exemplo: uma mesa de estudos diferenciada a sua necessidade, banheiros adaptados, colocação de rampas, colocar corrimões próximo de bebedouros, tapetes antiderrapantes para áreas escorregadias, dentre outras. (BRASIL, 2015)

Sabendo do seu dever, a escola deve incluir o aluno adaptando os espaços, para propiciar a igualdade de oportunidades.

Para os cuidados em sala de aula e para garantirmos a qualidade do ensino e o desenvolvimento das crianças com deficiência física, devemos ter alguns cuidados como: (MANZINI \& DELIBERATO, 2002) 
- O professor regular precisa saber se a criança toma algum medicamento e qual o efeito que pode causar.

- O maior desafio do professor não será a capacidade de aprender, mas sim da coordenação motora do aluno, por isto, o professor deverá adaptar seu material fazendo se possível alguns ajustes, como, por exemplo, ele poderá fazer um lápis adaptado com espaguete de piscina.

- Para melhor condição da aprendizagem, o professor deve propiciar uma adaptação para o aluno, retirando cadeiras, abrindo espaços, para que ele venha desenvolver melhor as atividades.

- Para facilitar as aulas e ainda ajudar no desenvolvimento do aluno o professor pode colocar em prática atividades, jogos e brincadeiras que trabalhem a psicomotricidade, utilizando dessa estratégia a criança terá mais autonomia na sala, e o processo de inclusão acontecerá naturalmente.

- Sempre que possível conversar com a família do aluno, e interagir também com os terapeutas para obter informações para adaptar o aluno em sala.

- Questionar com os pais a alimentação do aluno, saber se ele tem refluxo ou algum problema referente a deglutição de alimentos.

- Observar constantemente a postura do aluno, evitando a má postura.

\section{METODOLOGIA}

No que concerne o procedimento no orbe metodológico para elaboração deste artigo, se caracteriza como uma pesquisa qualitativa que primou pelo exame minucioso da temática a partir de pesquisa bibliográfica. Assim, as discussões

suscitadas por este trabalho são importantes contribuições para os profissionais que estão inseridos no labor pedagógico. (RODRIGUES e LIMENA, 2016)

\subsection{RESULTADOS E DISCUSSÃO}

Identificamos nesta pesquisa bibliográfica que os procedimentos adotados para aperfeiçoar o trabalho do professor apresenta vários estudos acadêmicos a qual foram pontuados.

\section{CONSIDERAÇÕES FINAIS}

De fato, a inclusão traz para todos, o desafio de mudarmos nossa forma de ver o mundo, de agir e de pensar. Temos uma grande oportunidade quando convivemos com pessoas que são diferentes, e é na escola que começamos a mudar este olhar, com o papel 


\section{Revista Ibero-Americana de Humanidades, Ciências e \\ Educação \\ Produção e democratização do conhecimento na Ibero-América}

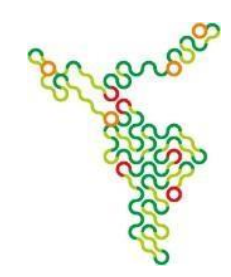

fundamental, é na escola que são ensinadas as primeiras regras de convivência em sociedade, é onde nos deparamos com a convivência de pessoas muito diferentes de nós, desde o princípio da formação da nossa identidade.

Complementamos o trabalho com uma grande reflexão para o respeito às diferenças e para o despertar da aprendizagem do professor, pontuando que sua qualificação profissional aprimora seus conhecimentos para sala de aula, para que realmente a conquista do respeito às diferenças, a aceitação, a solidariedade e a educação inclusiva aconteçam de fato.

\section{REFERÊNCIAS}

American Psychiatric Association. DSM-5: Manual diagnóstico e estatístico de transtornos mentais. Artmed Editora, 2014.

BRASIL, C. F. (2010). Constituição da República Federativa do Brasil de 1988.

Parâmetros Curriculares Nacionais: Adaptações Curriculares, Estratégias para a Educação de Alunos com necessidades Educacionais Especiais, 1999.

, L. D. B. (2015). Lei 9394/96-Lei de Diretrizes e Bases da Educação Nacional. $\overline{\overline{\text { Disponivel }}}$ http://www. planalto. gov. br/ccivil_03/leis/l9394. htm. Acesso em 12/11/2018, 30 .

Ministério da Educação. (2002). Diretrizes nacionais para a educação especial na educação básica. MEC/SEESP.

BIANOR, A. M. O processo de inclusão de alunos com síndrome de down no ensino regular: realidade e possibilidades, 2017.

CARNEIRO, M. A. O acesso de alunos com deficiência às escolas e classes comuns: possibilidades e limitações. Editora Vozes. 14-50, 2007.

DA SILVA, L. M. Educação inclusiva e formação de professores. Cuiabá-MT: TCC, Setembro, 2009.

CARVALHO, R. Elder. Educação Inclusiva: com os pingos nos “is”. 119-131,80-82, 2016.

DUTRA, C. P. Política Nacional de educação especial na perspectiva da educação inclusiva, 2007.

HONORA, M., \& FRIZANCO, M. L. E. Esclarecendo as deficiências. São Paulo: Cirando Cultural. 14-30. 50-80, 2009.

JOIA, M. A Inclusão de Crianças na Escola. Rio de Janeiro: Wak Editora. 21-35, 2018. 


\section{Revista Ibero-Americana de Humanidades, Ciências e \\ Educação \\ Produção e democratização do conhecimento na Ibero-América}

MANZINI, E. J., \& Deliberato, D. (2002). Portal de ajudas técnicas para a educação: equipamento e material pedagógico para educação, capacitação e recreação da pessoa com deficiência-recursos pedagógicos adaptados. Brasília: Mec/Seesp, 1.

PEREIRA, M. H. Educação inclusiva, 2017.

PLETSCH, M. D. A formação de professores para a educação inclusiva: legislação, diretrizes políticas e resultados de pesquisas. Educar em Revista, (33), 143-156, 2009.

SMITH, D. D. (2009). Introdução à educação especial: ensinar em tempos de inclusão. Artmed Editora.

RODRIGUES, Maria Lucia; LIMENA, Maria Margarida Cavalcanti (Orgs.). Metodologias multidimensionais em Ciências Humanas. Brasília: Líber Livros Editora, 2006.

ROPOLI, E. A., Mantoan, M. T. E., \& Santos, M. T. D. C. T. (2010). A Educação Especial na Perspectiva da Inclusão Escolar: a escola comum inclusiva. In A educação especial na perspectiva da inclusão escolar: a escola comum inclusiva. 20-28, 2010.

ZAPPAROLI, K. 2014). Estratégias lúdicas para o ensino da criança com deficiência. Rio de Janeiro: Wak Editora, 2014. 